\title{
Pathology and molecular analysis of Hapalotrema mistroides (Digenea: Spirorchiidae) infecting a Mediterranean loggerhead turtle Caretta caretta
}

\author{
M. Santoro ${ }^{1, *}$, F. Di Nocera ${ }^{1}$, D. Iaccarino ${ }^{1}$, S. P. Lawton ${ }^{2}$, A. Cerrone ${ }^{1}$, \\ B. degli Uberti ${ }^{1}$, M. D'Amore ${ }^{1}$, A. Affuso ${ }^{3}$, S. Hochscheid ${ }^{3}$, F. Maffucci ${ }^{3}$, G. Galiero ${ }^{1}$ \\ ${ }^{1}$ Istituto Zooprofilattico Sperimentale del Mezzogiorno, Via Salute n. 2, 80055 Portici, Italy \\ ${ }^{2}$ Molecular Parasitology Laboratory, School of Life Sciences, Pharmacy and Chemistry, Kingston University, \\ Kingston upon Thames, Surrey KT1 2EE, UK \\ ${ }^{3}$ Stazione Zoologica Anton Dohrn, Villa Comunale, 80121 Naples, Italy
}

\begin{abstract}
Turtle blood flukes belonging to the family Spirorchiidae (Digenea) represent a major threat for sea turtle health and are considered the most important parasitic cause of turtle stranding and mortality worldwide. Despite the large diversity of spirorchiid species found globally, there are only 2 records for free-ranging Mediterranean sea turtles that date back to the late 1800s involving just Hapalotrema mistroides Monticelli, 1896. This study describes the first fatal confirmed case of spirorchiidiasis in a free-ranging Mediterranean loggerhead turtle Caretta caretta (Linnaeus) and, owing to the complexities of taxonomic identification of these parasites, provides the first molecular characterization and phylogenetic analysis of $H$. mistroides from the Mediterranean Sea. The loggerhead turtle showed cachexia and digestive disorders associated with severe damage to the pancreas and intestinal ganglia, caused by deposition of Hapalotrema eggs forming granulomas. Massive Hapalotrema egg emboli in several tissues and organs and encephalitis were the most probable contributions to the death of the turtle. The congruence between the phylogenetic analysis of both the ITS2 and 28S rDNA resolved the Italian and USA $H$. mistroides as the same species, confirming the parasite identification. The case here described clearly indicates that the blood flukes should be considered in the differential diagnosis of Mediterranean sea turtle diseases.
\end{abstract}

KEY WORDS: Spirorchiids • Blood flukes · Pathological changes · ITS2 - 28S rDNA · Mediterranean Sea

\section{INTRODUCTION}

The Spirorchiidae Stunkard, 1921, a family of blood flukes within the superfamily Schistosomatoidea (Platyhelminthes: Digenea), parasitize the cardiovascular system of marine and freshwater turtles. The Spirorchiidae comprises 21 genera, 10 of which exclusively parasitize sea turtles (Platt 2002, Orélis-Ribeiro et al. 2014, Roberts et al. 2016a,b). Spirorchiids produce vast numbers of eggs which penetrate the gut wall, migrate into the intestinal lumen and are eliminated into the external environment with the host's feces (Smith 1972). However, many eggs become lodged in tissues, leading to a granulomatous response and resulting in a disease presentation analogous to that of schistosomiasis in mammals (Smith 1972). These infections are considered the most important parasitic cause of stranding and mortality of sea turtles worldwide; however, incidental findings of infection with no associated clinical signs are also common (Santoro 
et al. 2007, Flint et al. 2010, Stacy et al. 2010a, Chen et al. 2012, Werneck et al. 2015a,b, Work et al. 2015). Most reports of marine spirorchiids are restricted to the tropics and sub-tropics, with a prevalence ranging from 30 to $100 \%$ depending on the turtle species and geographical area (Santoro et al. 2006, Flint et al. 2010, Stacy et al. 2010a, Chen et al. 2012, Werneck et al. $2015 a, b)$. Despite the large diversity of spirorchiid species which cause infection and occur in co-infections in turtles globally, there are only 2 old records in the Mediterranean involving a single species, Hapalotrema mistroides Monticelli, 1896, in the loggerhead Caretta caretta (Linnaeus) from the Gulf of Naples (Monticelli 1896) and in loggerhead and green turtle Chelonia mydas (Linnaeus) from Egypt (Looss 1899). Recently, Amphiorchis sp. Price, 1934 infecting vermetid gastropods and captive hatched neonates of loggerhead was found from the Oceanographic Aquarium in Valencia (Spain), and it was supposed that the infection came from mature turtles taken from the western Mediterranean (Cribb et al. 2017).

The most common spirorchiid infections recorded globally are caused by members of either or both Hapalotrema Looss, 1899 and Learedius Price, 1934 (Work et al. 2005, Santoro et al. 2006, 2007, Flint et al. 2010, Stacy et al. 2010a, Chen et al. 2012, Werneck et al. 2015a,b). Diagnosis of infections with these parasites has, to date, relied largely on fecal examination for eggs or on morphology of adult worms retrieved during necropsy (Greiner 2013). However, morphological features often overlap between spirorchiid species, making accurate taxonomic-based diagnosis a challenge, especially now that a number of studies have highlighted the occurrence of cryptic species within the genus Hapalotrema (Stacy 2008, Chapman et al. 2015). Chapman et al. (2015) illustrated in a recent molecular study that Learedius learedi Price, 1934 nested unequivocally among species of Hapalotrema, forming a Hapalotrema/Learedius group and bringing into question the acceptance of the genus Learedius. This highlighted the importance of phylogenetically accurate molecular characterization of spirorchiid species associated with disease, the need for DNA-based tests for diagnostics and understanding transmission, especially as marine spirorchiid life cycles are still poorly known (Smith 1972, Stacy 2008, Stacy et al. 2010b, Cribb et al. 2017).

This study describes the first fatal confirmed case of spirorchiidiasis in a free-ranging Mediterranean loggerhead turtle and, owing to the complexities of taxonomic identification of these parasites, provides the first molecular characterization and phylogenetic analysis of $H$. mistroides from the Mediterranean Sea.

\section{MATERIALS AND METHODS}

\section{Necropsy and case description}

On June 16, 2015, a loggerhead female weighing $26.8 \mathrm{~kg}$ and measuring $66.5 \mathrm{~cm}$ of curved carapace length was found stranded alive at Santa Marinella $\left(42^{\circ} 02^{\prime} 49^{\prime \prime} \mathrm{N}, 11^{\circ} 52^{\prime} 21^{\prime \prime} \mathrm{E}\right)$, Civitavecchia, on the coast of Latium (central western Italy) and hospitalized at the Sea Turtle Rescue Center of the Stazione Zoologica Anthon Dohrn of Naples. The turtle was in a poor condition, lethargic and exhibited diminished tail and cloacal reflexes. Radiograph and ultrasound examinations of the coelomic cavity showed impaction of the large intestine and rectum obstruction by dry fecal balls (the largest was approximately $18 \mathrm{~cm}$ in diameter) containing mollusk shells, sea urchin, and crab fragments. The turtle received symptomatic treatment for $20 \mathrm{~d}$ and then emergency surgery was performed to remove the obstruction, but she died the following day. The treatment consisted of fluid and antibiotic therapies, enema with saline solution and $10 \%$ mineral oil to remove fecal balls, metoclopramide to stimulate the intestinal motility, and supplementation with iron and vitamins.

At necropsy, the brain, heart, blood vessels, trachea, lungs, urinary bladder, liver, gallbladder, kidneys, pancreas, oviducts, esophagus, stomach, intestine and body cavity were examined separately for helminths with a dissecting microscope (Greiner et al. 1980, Snyder \& Clopton 2005). Worms were washed in saline solution and preserved in $70 \%$ ethanol; digeneans were stained with red carmine, dehydrated using a graded alcohol series, cleared in methyl salicylate and mounted on slides in Canada balsam for morphological identification. Specimens of Hapalotrema mistroides were identified following the identification key proposed by Platt \& Blair (1998).

Standard sedimentation methods were used to detect parasite eggs from feces (Greiner 2013). Samples for histological examination of all organs and tissues examined for parasites were fixed in $10 \%$ neutral phosphate-buffered formalin and processed by routine methods into paraffin blocks which were cut into $3 \mu \mathrm{m}$ thick sections and stained with hematoxylin and eosin. Histologically, the severity of lesions associated with spirorchiid infection was scored for each examined tissue as follows: 0 (absent), 1 (mild: 1 to several small, scattered granulomas per low power [ $\times 20$ ] field, each centered on $\leq 5$ spirorchiid eggs), 2 (moderate: 1 to several granulomas centered on $>5$ to 10 spirorchiid eggs per $\times 20$ field, with some effacement of tissue architecture by granulomas), or 3 
(severe: numerous smaller granulomas, each centered on $>5$ eggs, or large, often coalescing granulomas and/or sheets of inflammatory cells centered on $\geq 10$ to hundreds of eggs, both with extensive effacement of tissue architecture) (Flint et al. 2010).

\section{Molecular analyses}

Genomic DNA was extracted from a single individual of $H$. mistroides obtained from the described necropsy using the Qiagen DNeasy blood and tissue kit following the manufacturer's instructions. Using primers and methods described by Chapman et al. (2015), a short ITS2 fragment was chosen for characterization of $H$. mistroides alongside a fragment of the 28S rDNA using primers and protocols developed by Olson et al. (2003). Both markers were used as a barcode sequence for the Italian specimen of $H$. mistroides, as published reference sequences for ribosomal gene fragments are available for comparison for this species and several other members of the Spirorchiidae compared to typical mitochondrial cox1 barcodes. Also, the 28S fragment has been shown to aid in accurately resolving phylogenetic relationships within the Digenea, and the ITS2 region has been suggested to resolve fine-scale species differences (Olson et al. 2003, Orélis-Ribeiro et al. 2014, Chapman et al. 2015). The PCR reaction was performed using $12.5 \mu \mathrm{l}$ of DreamTaq ${ }^{\mathrm{TM}}$ PCR master mix $(2 \times$ DreamTaq buffer, $0.4 \mathrm{mM}$ of each dNTP, $4 \mathrm{mM}$

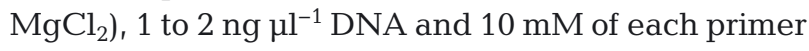
with a final reaction of $25 \mu \mathrm{l}$ with PCR-grade water; the sample was then run on a Veriti 96-well (Applied Biosystems ${ }^{\mathrm{TM}}$ ) PCR machine. The resultant amplicon was visualized on a $1 \%$ agarose gel stained with GelRed (Bioline) using only $5 \mu$ l of PCR product, and the remaining $20 \mu \mathrm{l}$ PCR products were sequenced at the Natural History Museum, London, using fluorescent dye terminator sequencing kits (Applied Biosystems ${ }^{\mathrm{TM}}$ ) and run on an Applied Biosystems 3730KL automated sequencer. Resultant forward and reverse sequences were assembled and edited using Bioedit (Hall 1999), and BLASTn (http://blast.ncbi.nlm.nih.gov/) searches were performed on consensus sequences to provide an initial identification of the parasite. For both the ITS2 and 28S, phylogenetic analysis was performed using representative DNA sequences from the same species of Spirorchiidae blood flukes from sea turtles where possible including Hapalotrema, Learedius and Carettacola Manter \& Larson 1950 (Chapman et al. 2015). There were subtle differences between the numbers of ITS2 and 28S sequences available for dif- ferent species, and where possible, the majority if not all ITS2 or 28S sequences for a particular species were used for analysis. Three species of Schistosomatidae including Schistosoma edwardiense, Schistosomatium douthitti and Gigantobilharzia huronensis were used as outgroups, as they represent a paraphyletic sister group to the marine spororchiids (OrélisRibeiro et al. 2014). Alignments were performed using MUSCLE (www.ebi.ac.uk), and as in Chapman et al. (2015), subsequent phylogenetic analysis was performed using maximum likelihood (ML) in MEGA6 (Tamura et al. 2013). The ITS2 ML analysis was performed under the conditions of the Kimura 2-parameter model, and the 28S analysis was performed under the conditions of the GTR+G model; in both cases, models identified in MEGA6 based on the lowest Bayesian information criterion relative to the other models tested for and nodal support values were estimated using 1000 bootstrap replicates. To measure diversity and divergence between $H$. mistroides and other species of Hapalotrema, uncorrected p-distance was also calculated using MEGA6 (Tamura et al. 2013) to ensure that $H$. mistroides could be delineated as a separate species.

\section{RESULTS}

\section{Necropsy and associated pathology}

Post-mortem examination of the turtle revealed cachexia, absence of fat reserves, ascites, gelatinous consistency, atrophy and discoloration of the pectoral muscles. The spleen was congested, and the serosa of the small intestine and pancreas was focally thickened with diffuse presence of black spots up $2 \mathrm{~mm}$ in diameter showing extensive transmural granulomatous lesions (Fig. 1); black raised foci about $1 \mathrm{~mm}$ in diameter were also observed on the intestinal mucosal surface.

Three adult cardiovascular flukes identified as Hapalotrema mistroides were found only from the spleen. Specimens possessed 8 pre-ovarian and 12 postovarian testes and a genital pore located in the anterior half of the body. A voucher specimen of $H$. mistroides is deposited in the Natural History Museum in London (NHMUK.2017.1.6.1.). Hapalotrema eggs (Fig. 2A,B) found in the intestinal lumen were 450.6 by $42 \mu \mathrm{m}$ ( $\mathrm{n}=10$ ), brown and fusiform, with 2 long hooked polar processes (Fig. 2A). Live miracidia (mean length 84.7 by $31 \mu \mathrm{m}, \mathrm{n}=10$ ) were present in the central oval portion of the eggs (Fig. 2A). Other parasites found were 3 individuals of 


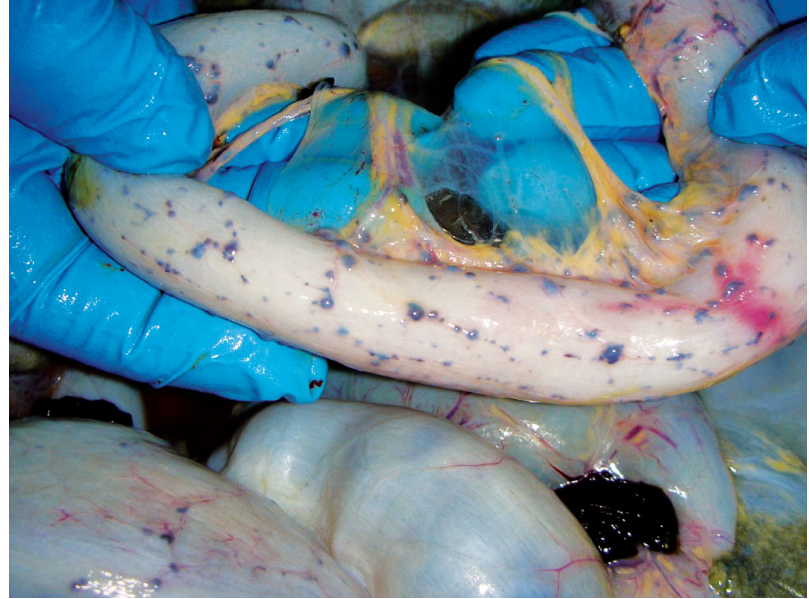

Fig. 1. Duodenum of infected loggerhead, showing miliary trematode egg granulomas (black spots) on serosa

Orchidasma amphiorchis Braun, 1899 (Digenea) and a single Rhytidodes gelatinosus Rudolphi, 1819 (Digenea), both from the intestinal lumen.

Hapalotrema egg granulomas were found in the pancreas (Fig. 2B), intestine (Fig. 2C), liver, lungs, kidneys, urinary bladder and spleen (Fig. 2D). Severity of lesions was classified as severe in all above cited organs except the liver and urinary bladder, where lesions were classified as mild, although the largest and the highest density of egg granulomas were observed in the pancreas, spleen and intestine. The pancreatic lobes showed large multicentric and coalescent granulomas replete with Hapalotrema eggs effacing the ducts and parenchyma of pancreatic glands (Fig. 2B). A core of hypereosinophilic debris was present and surrounded by histiocytic infiltrates and multinucleated giant cells. The intestinal serosa was markedly thickened, showing the vascular lumen of smaller vessels partially or totally obliterated by egg emboli (Fig. 2C). Egg granulomas were observed throughout the whole intestinal wall but were larger in the muscularis externa and serosa, where they caused significant disorganization of the normal architecture including that of intestinal ganglia. The brain showed extensive areas of encephalomalacia, with medial hypertrophy of arteriolar walls and lymphocytic and heterophil infiltrates (Fig. 2E). Spirorchiid egg embolisms were found histologically from lungs, kidneys, pancreas, spleen and intestine.

\section{Molecular analyses}

The initial BLASTn searches based on the resultant ITS2 (Acc: KY499798) and 28S sequences (Acc:
KY499799) indicated that Italian H. mistroides was most similar to $H$. mistroides from Florida (USA) (Acc: GU937893 and KU892016, respectively). The ITS2 phylogenetic analysis to identify the taxonomic position of $H$. mistroides was performed on an alignment approximately $270 \mathrm{bp}$ in length containing 11 sequences representing 7 spirorchiid species primarily from the USA and Australia and produced a wellsupported phylogeny with nodal bootstraps greater than 50. The overall topology of ML phylogeny was identical to that presented in Chapman et al. (2015) in relation to the position and relationship of species (Fig. 3). The Italian and the Floridian H. mistroides fell out together, forming well-supported sister taxa, and showed to be a sister species to $H$. postorchis. The 28S phylogenetic analysis, based on a final alignment of $636 \mathrm{bp}$ in length consisting of 12 sequences representing 8 spirorchiid species, showed the same overall topology as the ITS2 analysis except for the position of Spirorchiidae sp. Spirorch83. In the ITS2 phylogeny, it fell within a discrete clade containing $H$. mistroides and $H$. postorchis but appeared basal to the Hapalotrema/Learedius group. The 28S ML analysis appeared to have higher nodal support bootstrap values compared to the ITS2 and confirmed the identity of $H$. mistroides from Italy as well as its taxonomic position as a sister species to $H$. postorchis (Fig. 3). Comparisons of uncorrected p-distance showed there to be only a $1.4 \%$ difference in the ITS 2 and a $0.2 \%$ difference in the $28 \mathrm{~S}$ between the Italian and Floridian $H$. mistroides. However, when p-distances for both $H$. mistroides isolates were compared to $H$. postorchis, the ITS2 appeared 4.2 to $5.6 \%$ different and the $28 \mathrm{~S}$ appeared 2.4 to $2.6 \%$ different, indicating distinct species based on the divergence range of ribosomal gene fragments between species of marine trematodes as described in McNamara et al. (2014).

\section{DISCUSSION}

Hapalotrema mistroides has been shown to be pathogenic in the Atlantic, with a single study showing the parasite to be in $85 \%$ of stranded loggerhead turtles examined and to be associated with the most severe endarteritis pathologies, regardless of the presence or absence of co-infections with other spirorchiid species (Stacy et al. 2010a). Flint et al. (2010), in a $4 \mathrm{yr}$ stranding survey of green turtles in Australia, found a wide range of digestive disorders including impaction caused by torsion, obstruction by dry fecal balls and intestinal constrictions in $11.8 \%$ of reported diseases, contributing to $5.1 \%$ of deaths. The etiol- 


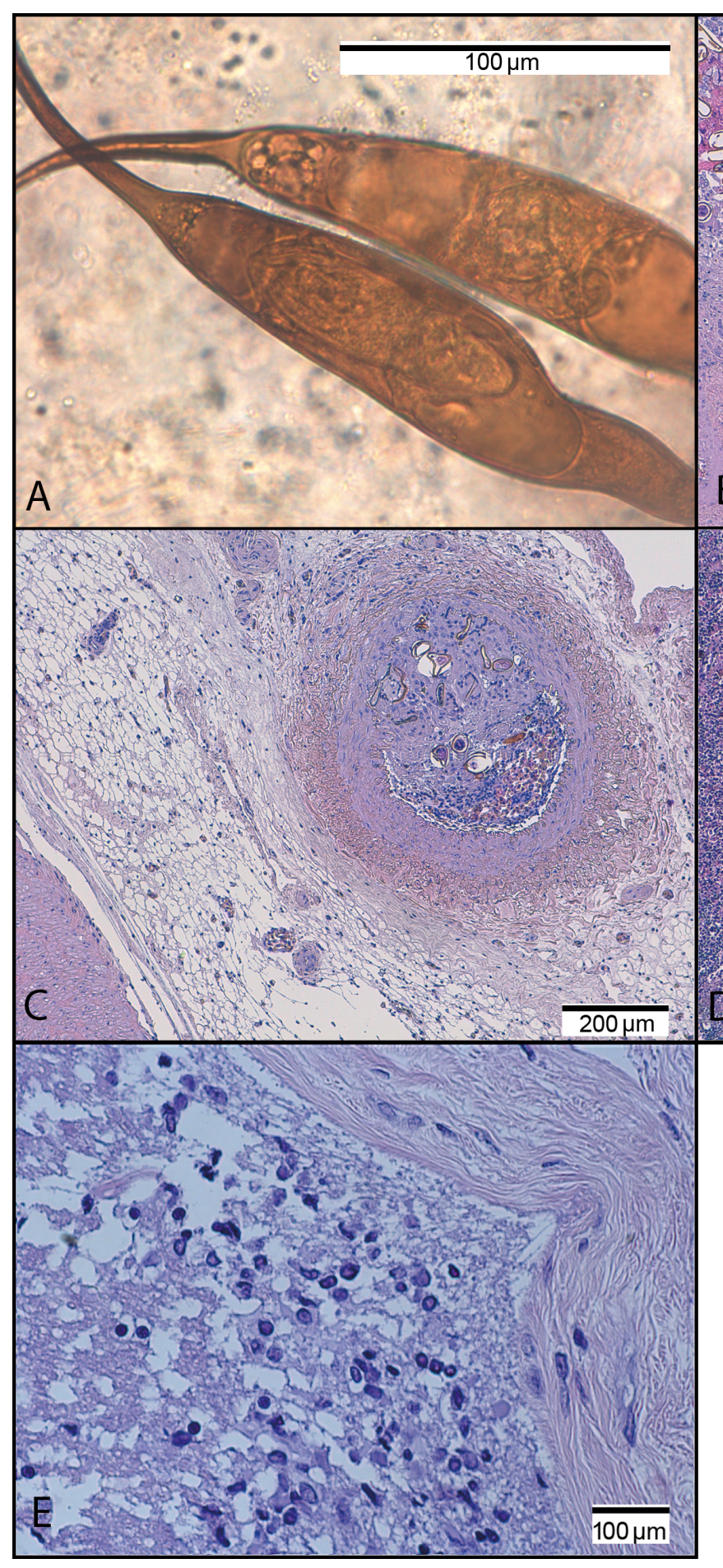

ogy was not indicated, but gastrointestinal disorders occurred with moderate to severe infection with unidentified spirorchiids in $60 \%$ of cases. We hypothesize that digestive disorders found here might be associated with severe damage to the pancreas and intestinal ganglia, both caused by spirorchiid egg granulomas. Granulomas may result in alteration of

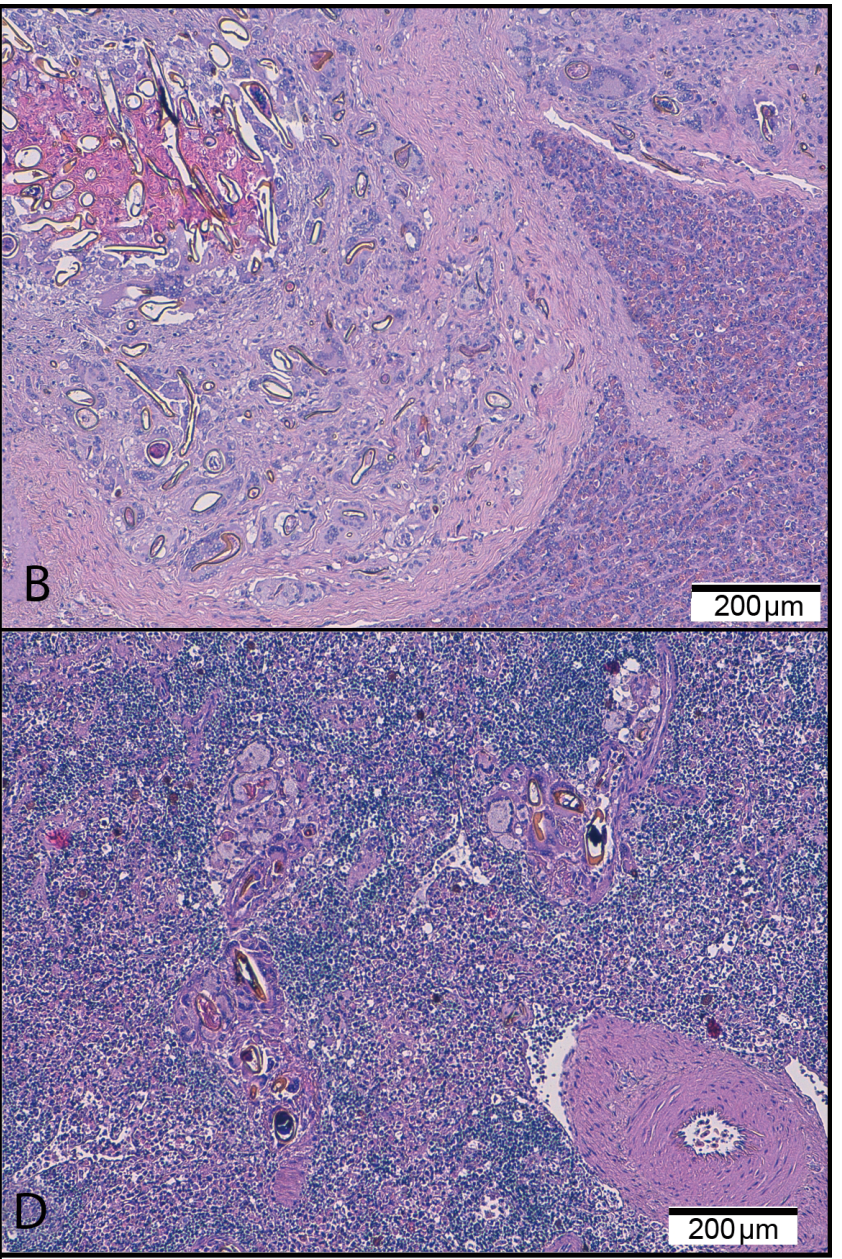

Fig. 2. (A) Eggs compatible in morphology with those of Hapalotrema mistroides from the feces of the infected loggerhead; note the miracidium in the lower egg. (B) Pancreas: large coalescent granulomas replete with trematode eggs effacing ducts and parenchyma of pancreatic glands and surrounding a core of hypereosinophilic debris (necrosis) in upper left. (C) Intestine: vascular trematode egg-associated embolism in intestinal serosa; note the near-complete obstruction of the vessel lumen. (D) Spleen: multiple trematode egg-induced granulomas surrounded by multinucleate giant cells and histiocytes. (E) Brain: lymphocytic and heterophil infiltration

the secretion of pancreatic enzymes and intestinal ganglia, responsible for digestive functions and intestinal peristalsis, respectively. Massive Hapalotrema egg emboli and encephalitis were the most probable contributions to the death of the turtle.

In loggerhead and green turtles from the coast of Egypt, Looss (1899) reported gross changes in the 


\section{A) Maximum likelihood reconstruction of ITS2}

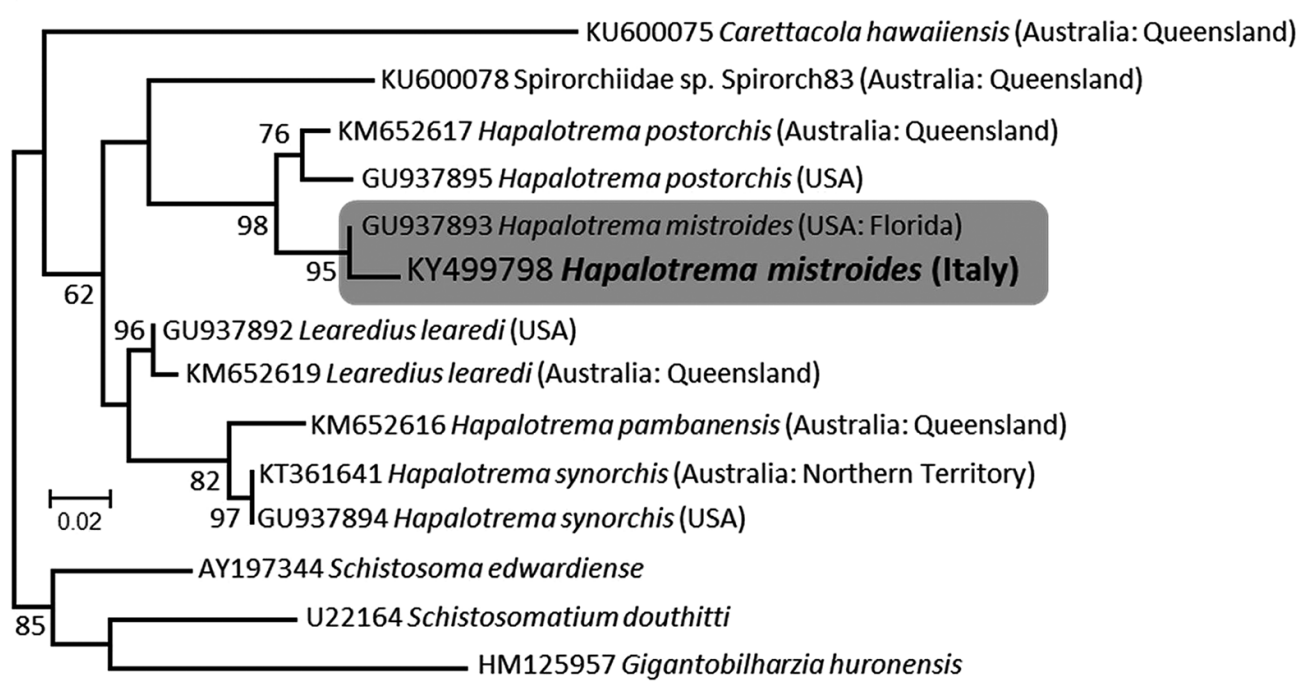

B) Maximum likelihood reconstruction of $28 \mathrm{~S}$

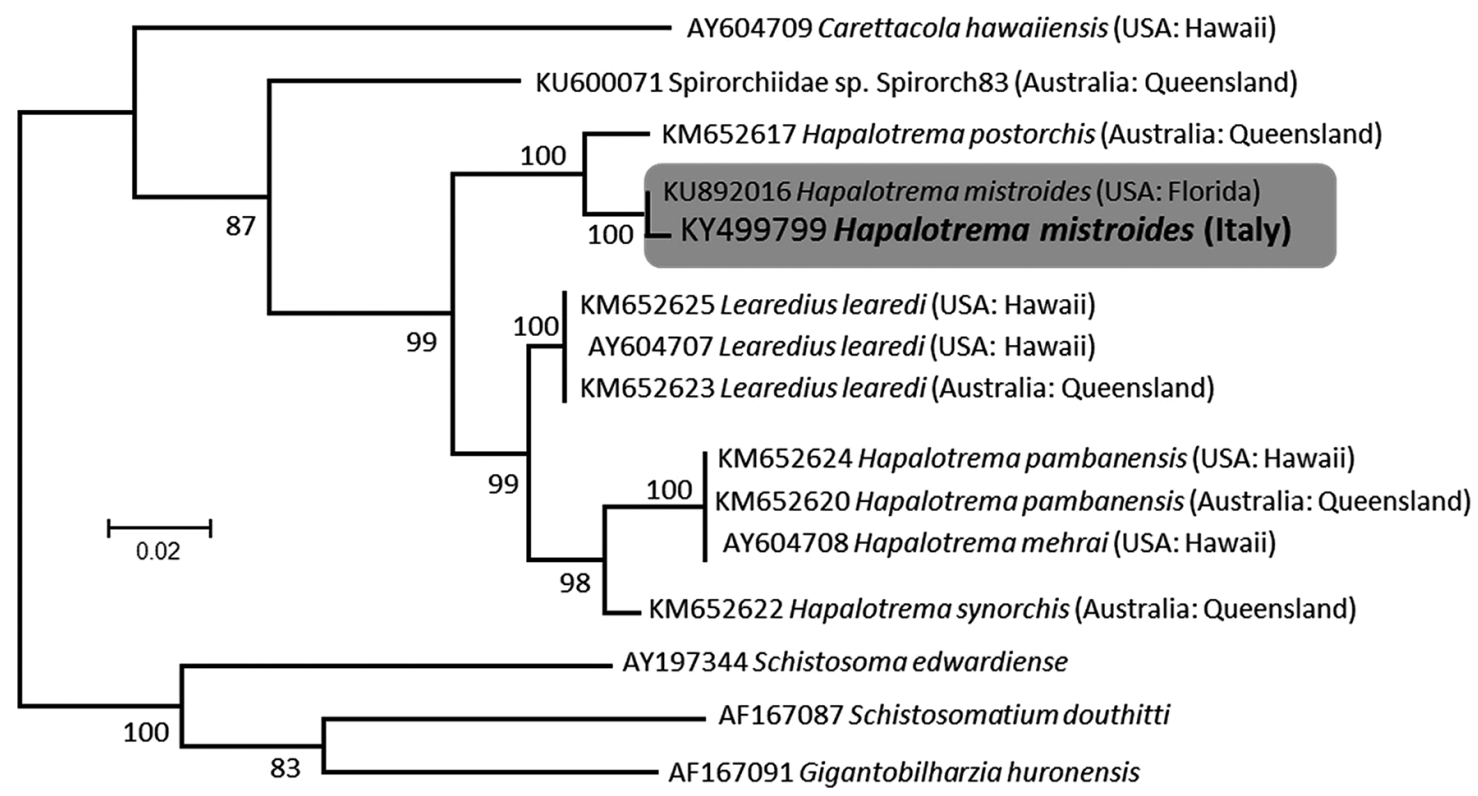

Fig. 3. Maximum likelihood phylogenetic reconstruction of the position of Mediterranean Hapalotrema mistroides from Italy in relation to other spirorchiid species based on partial (A) ITS2 and (B) 28S fragments. Nodal supports are bootstrap values based on 1000 replicates; only values $>50$ are shown

vascular intima and endothelium associated with the attachment of Hapalotrema specimens. However, since then, all other parasitological and pathological studies in sea turtles from the Mediterranean Sea or adjacent Atlantic areas failed to reveal any cardiovascular fluke infection (Sey 1977, Aznar et al. 1998, Manfredi et al. 1998, Valente et al. 2009, Santoro et al. 2010a,b, Orós et al. 2016). This suggests that spirorchiid infections occur just occasionally in the Mediterranean Sea or may persist in low intensity.
The occasional finding of $H$. mistroides in Mediterranean waters could be related to the lower water temperature relative to the tropical areas, resulting in slower transmission cycles of the parasite and thus reducing the possibility of infection for sea turtles. Experimental studies on freshwater turtles have indicated that many aspects of spirorchiid development are temperature dependent. For example, it was demonstrated that the eggs of the freshwater Spirorchis elegans placed at refrigeration temperature 
(from 3 to $6^{\circ} \mathrm{C}$ ) for $76 \mathrm{~d}$ did not hatch but did not lose viability (Goodchild \& Kirk 1960, Smith 1972). Flint et al. (2010) also suggested that the increase of severity of spirorchiidiasis in Australian green turtles during warmer seasons could be directly related to increased cercarial emergence, an increased availability of mollusc intermediate hosts and the fact that warmer temperatures stimulate greater egg production in worms already infecting turtles. However, this remains highly theoretical, as there are poor published data on the life cycle of marine spirorchiids (Stacy et al. 2010b, Cribb et al. 2017). It is more likely that the life cycle of $H$. mistroides is not maintained in the locality due perhaps to the absence of the intermediate host in the Mediterranean Sea, and the loggerhead turtle studied here could have been infected in another area of the globe. In addition, given the confirmed movement of sea turtles between the Mediterranean and the Atlantic coast of the USA (Bowen \& Karl 2007, Shamblin et al. 2014) where other species of spirorchiids are documented (Stacy 2008), it would not be surprising if other species of spirorchiids are found in sea turtles in the Mediterranean Sea.

The phylogenetic analysis of the ITS2 region showed the same tree topology as that illustrated in Chapman et al. (2015), which was supported and verified by the original 28S analysis performed in this study. Both analyses confirmed the Italian and Floridian (USA) $H$. mistroides to be the same species, only divergent by $0.2 \%$ in the $28 \mathrm{~S}$ and up to $1.4 \%$ in the ITS2. Although the molecular data presented in this study are limited, they indicate a low level of divergence between the Italian and Floridian populations. Distribution of the parasites is intimately linked with that of their definitive host, and genetic studies have shown that there is movement between populations of loggerhead from the Pacific, Indian and Atlantic oceans, illustrating the wide migratory range and cosmopolitan distribution of loggerhead turtles, which could account for the low level of divergence in the parasite populations (Bowen \& Karl 2007, Shamblin et al. 2014). The small genetic differences between $H$. mistroides from Italy and Florida are noteworthy given that differences were also found between specimens of $H$. postorchis collected from Atlantic and Pacific regions (Chapman et al. 2015). H. mistroides resolves as a unique paraphyletic sister species to $H$. postorchis, further confirming it as a valid species and providing further support to the accuracy of the species identification made in this current study. However, detailed comparative genetic analysis of $H$. mistroides populations from the Atlantic and the Mediterranean from more extensive sampling of parasites and using more molecular markers will be needed to disentangle the origin of $H$. mistroides and its true relationship with $H$. postorchis.

The case here described clearly indicates that these flukes should be considered in the differential diagnosis of Mediterranean sea turtle diseases, although it appears that the risk of spirorchiid infection in the Mediterranean Sea is low. Detection of spirorchiids and associated lesions requires a targeted approach that includes dissection of the cardiovascular system, detailed examination of vascular compartments and examination of all tissues (both grossly and histologically) as well as fecal examination (Snyder \& Clopton 2005, Stacy 2008, Greiner 2013). Integration of detailed health assessment and parasite detection and identification methods is required to gain a better understanding of these parasites and their significance in endangered Mediterranean loggerhead turtles.

\section{LITERATURE CITED}

Aznar FJ, Badillo FJ, Raga JA (1998) Gastrointestinal helminths of loggerhead turtles (Caretta caretta) from the western Mediterranean: constraints on community structure. J Parasitol 84:474-479

*Bowen BW, Karl SA (2007) Population genetics and phylogeography of sea turtles. Mol Ecol 16:4886-4907

* Chapman PA, Cribb TH, Blair D, Traub RJ, Kyaw-Tanner MT, Flint M, Mills PC (2015) Molecular analysis of the genera Hapalotrema Looss, 1889 and Learedius Price, 1934 (Digenea: Spirorchiidae) reveals potential cryptic species, with comments on the validity of the genus Learedius. Syst Parasitol 90:67-79

* Chen H, Kuo RJ, Chang TC, Hus CK, Bray RA, Chen IJ (2012) Fluke (Spirorchiidae) infections in sea turtles stranded on Taiwan: prevalence and pathology. J Parasitol 98: $437-439$

Cribb TH, Crespo-Picazo JL, Cutmore SC, Stacy BA, Chapman PA, García-Párraga D (2017) Elucidation of the first definitively identified life cycle for a marine turtle blood fluke (Trematoda: Spirorchiidae) enables informed control. Int J Parasitol 47:61-67

Flint M, Patterson-Kane JC, Limpus CJ, Mills PC (2010) Health surveillance of stranded green turtles in southern Queensland, Australia (2006-2009): an epidemiological analysis of causes of disease and mortality. EcoHealth 7: 135-145

Goodchild CG, Kirk DE (1960) The life history of Spirorchis elegans Stunkard, 1923 (Trematoda: Spirorchiidae) from the painted turtle. J Parasitol 46:219-228

Greiner EC (2013) Parasites of marine turtles. In: Wyneken J, Lohmann KJ, Musick JA (eds) The biology of sea turtles, Vol 3. CRC Press, Boca Raton, FL, p 427-446

Greiner EC, Forrester JJ, Jacobson ER (1980) Helminths of mariculture-reared green turtles (Chelonia mydas) from Grand Cayman, British West Indies. Proc Helminthol Soc Wash 47:142-144

Hall TA (1999) BioEdit: a user friendly biological sequence alignment program editor and analysis program for Windows 95/98/NT. Nucleic Acid Symp Ser 41:95-98 
Looss A (1899) Weitere Beiträge zur Kenntniss der Trematoden-Fauna Aegyptens, zugleich Versuch einer natürlichen Gliederung des Genus Distomum Retzius. Zool Jb Abt Syst 12:521-784

Manfredi MT, Piccolo G, Meotti C (1998) Parasites of Italian sea turtles. II. Loggerhead turtles (Caretta caretta Linnaeus, 1758). Parassitologia 40:305-308

McNamara MKA, Miller TL, Cribb TH (2014) Evidence for extensive cryptic speciation in trematodes of butterfly fishes (Chaetodontidae) of the tropical Indo-West Pacific. Int J Parasitol 44:37-48

Monticelli FS (1896) Di un ematozoo della Thalassochelys caretta Linn. Int Mschr Anat Physiol 13:141-172

Olson PD, Cribb TH, Tkach VV, Bray RA (2003) Phylogeny and classification of the Digenea (Platyhelminthes: Trematoda). Int J Parasitol 33:733-755

* Orélis-Ribeiro R, Arias CR, Halanych KM, Cribb TH, Bullard SA (2014) Diversity and ancestry of flatworms infecting blood of nontetrapod craniates 'fishes'. Adv Parasitol 85: 1-64

Orós J, Montesdeoca N, Camacho M, Arencibia A, Calabuig $P$ (2016) Causes of stranding and mortality, and final disposition of loggerhead sea turtle (Caretta caretta) admitted to a wildlife rehabilitation center in Gran Canaria Island, Spain (1998-2014): a long-term retrospective study. PLOS ONE 11:e0149398

Platt TR (2002) Family Spirorchiidae Stunkard 1921. In: Gibson DI, Jones A, Bray RA (eds) Keys to the Trematoda, Vol 1. CABI Publishing, Wallingford, p 453-467

Platt TR, Blair D (1998) Redescription of Hapalotrema mistroides (Monticelli, 1896) and Hapalotrema synorchis Luhman, 1935 (Digenea: Spirorchidae), with comments on other species in the genus. J Parasitol 84:594-600

Roberts JR, Platt TR, Orélis-Ribeiro R, Bullard SA (2016a) New genus of blood fluke (Digenea: Schistosomatoidea) from Malaysian freshwater turtles (Geoemydidae) and its phylogenetic position within Schistosomatoidea. J Parasitol 102:451-462

Roberts JR, Orelis-Ribeiro R, Dang BT, Halanych KM, Bullard SA (2016b) Blood flukes of Asiatic softshell turtles: revision of Coeuritrema Mehra, 1933 (Digenea: Schistosomatoidea) and a new species infecting Chinese softshell turtles, Pelodiscus sinensis (Trionychidae), from Vietnam. Folia Parasitol 63:31

Santoro M, Greiner EC, Morales JA, Rodríguez-Ortíz B (2006) Digenetic trematode community in nesting green sea turtles (Chelonia mydas) from Tortuguero National Park, Costa Rica. J Parasitol 92:1202-1206

Santoro M, Morales JA, Rodríguez-Ortíz B (2007) Spirorchiidiosis (Digenea: Spirorchiidae) and lesions associated with parasites in Caribbean green sea turtles (Chelonia mydas). Vet Rec 161:482-486

Santoro M, Badillo FJ, Mattiucci S, Nascetti G and others (2010a) Helminth communities of loggerhead turtles (Caretta caretta) from central and western Mediterranean Sea: the importance of host's ontogeny. Parasitol Int 59:367-375

Santoro M, Mattiucci S, Paoletti M, Liotta A, Degli Uberti B, Galiero G, Nascetti G (2010b) Molecular identification

Editorial responsibility: Thierry Work,

Honolulu, Hawaii, USA and pathology of Anisakis pegreffii (Nematoda: Anisakidae) infection in the Mediterranean loggerhead sea turtle (Caretta caretta). Vet Parasitol 174:65-71

Sey O (1977) Examination of helminth parasites of marine turtles caught along the Egyptian coast. Acta Zool Acad Sci Hung 23:387-394

* Shamblin BM, Bolten AB, Abreu-Gorbois FA, Bjorndal KA and others (2014) Geographical patterns of genetic variation in a broadly distributed marine vertebrate: new insights into loggerhead turtle stock structure from expanded mitochondrial DNA sequences. PLOS ONE 9: e85956

Smith SW (1972) The blood flukes (Digenea: Sanguinicolidae and Spirorchidae) of coldblooded vertebrates and some comparison with the schistosomes. Helminthol Abstr Ser A 41:161-194

* Snyder SD, Clopton RE (2005) New methods for the collection and preservation of spirorchiid trematodes and polystomatid monogeneans from turtles. Comp Parasitol 72: 102-107

Stacy BA (2008) Spirorchiid trematodes of sea turtles in Florida: associated disease, diversity, and life cycle studies. $\mathrm{PhD}$ dissertation, University of Florida, Gainesville

Stacy BA, Foley AM, Greiner E, Herbst LH and others (2010a) Spirorchiidiasis in stranded loggerhead Caretta caretta and green turtles Chelonia mydas in Florida (USA): host pathology and significance. Dis Aquat Org 89:237-259

Stacy BA, Frankovich T, Greiner EC, Alleman AR and others (2010b) Detection of spirorchiid trematodes in gastropod tissues by polymerase chain reaction: preliminary identification of an intermediate host of Learedius learedi. J Parasitol 96:752-757

* Tamura K, Stecher G, Peterson D, Filipski A, Kumar S (2013) MEGA6: Molecular Evolutionary Genetics Analysis version 6.0. Mol Biol Evol 30:2725-2729

*Valente AL, Delgado C, Moreira C, Ferreira S, Dellinger T, Pinheiro de Carvalho MAA, Costa G (2009) Helminth component community of the loggerhead sea turtle, Caretta caretta, from Madeira Archipelago, Portugal. J Parasitol 95:249-252

WWerneck MR, Binoti E, Martins IVF, Calais JA and others (2015a) Occurrence of Rhytidodoides similis Price, 1939 (Digenea: Rhytidododae) and lesions due to spirorchiid eggs in a green turtle Chelonia mydas Linnaeus, 1758 (Testudines, Cheloniidae) from Brazil. Comp Parasitol 82:291-295

*Werneck MR, Souza GB, Berger BC, Trazzi RB and others (2015b) Pathological changes by Hapalotrema postorchis Rao 1976 (Digenea: Spirorchiidae) in a green turtle Chelonia mydas Linnaeus 1758 (Testudines, Cheloniidae) from Brazil. Helminthologia 52:148-154

*Work TM, Balazs GH, Schumacher JL, Marie A (2005) Epizootiology of spirorchiid infection in green turtles (Chelonia mydas) in Hawaii. J Parasitol 91:871-876

Whork TM, Balazs GH, Summers TM, Hapdei JR, Tagarino AP (2015) Causes of mortality in green turtles from Hawaii and the insular Pacific exclusive of fibropapillomatosis. Dis Aquat Org 115:103-110

Submitted: November 15, 2016; Accepted: February 28, 2017 Proofs received from author(s): March 20, 2017 